Address for Correspondence: Dr. Jian-guo Li,

Department of Intensive Care Unit, Zhongnan Hospital of Wuhan University, Wuhan, Hubei Province, China.

E-mail: drljg181@ gmail.com

Jian-guo Li, Chief Physician, Professor, Ph.D. Supervisor, Discipline Leader of the Department of Intensive Care Unit, Zhongnan Hospital of Wuhan University; Deputy Director of the Chinese Society of Critical Care Medicine, Chinese Medica Associarion; Director Society of Critical Care Medicine, Hubei Medical Association; Commissioner of the Society of Critical Care Medical Doctors, Chinese Medical Doctor Association; Standing Commissioner of the Chinese Society of Critical Care Medicine, Chinese Association of Pathophysiology: Deputy Dirociator of the Hubei/Wuhan, Dociety Dir Critical Care Mei/Wuhan Society of Critical Care Medicine, Chinese of the Hubei Medical Association; Standing Commissioner of the Society of Anesthesiology, Hubei Medical Association; and a member of the editorial boards of several journals such as Journal of Internal Intensive Medicine.

\begin{tabular}{l}
\hline Access this article online \\
Website: \\
www.intern-med.com \\
DOI: \\
10.4103/2224-4018.141831 \\
Quick Response Code: \\
\hline
\end{tabular}

\title{
Role of genetic factors in the development of acute respiratory distress syndrome
}

\author{
Chang Liu, Jian-guo Li \\ Department of Intensive Care Unit, Zhongnan Hospital of Wuhan University, Wuhan, Hubei Province, China
}

\section{ABSTRACT}

Acute respiratory distress syndrome (ARDS) is not a genetic disease, but gene polymorphism influences the susceptibility, severity and prognosis of ARDS. It has been reported that the polymorphism of genes, such as angiotensin-converting enzyme and extracellular superoxide dismutase 3 genes, is related to ARDS. Research on the gene polymorphism of ARDS is currently in the preclinical stage, but it develops fast, In the future, ARDS-related gene polymorphism may play an important role in identifying susceptibility risk, assessing prognosis revealing new etiology and pathophysiological mechanisms, and optimizing diagnosis and treatment.

Key words: Acute respiratory distress syndrome, genetics, gene polymorphism

\section{INTRODUCTION}

Acute respiratory distress syndrome (ARDS) is not a genetic disease as it is not caused by any specific pathological chromosome or gene. However, individual differences have been found in the susceptibility, severity and prognosis of ARDS, the causes of which are unclear. ${ }^{[1]}$ The present study tends to assume that the polymorphism of genes is one of the important causes for the differences.

\section{Gene polymorphism}

Genetic polymorphism is the occurrence in the same population of two or more alleles at one locus due to normal mutation of DNA sequence. The alleles do not cause diseases, but in a certain condition may influence their carriers' susceptibility, clinical manifestations and responses to treatment of a disease. Thus, in a population, the same disease is different in susceptibility, clinical manifestations and responses to treatment. [2] Genetic polymorphism is classified as single nucleotide polymorphism (SNP), restriction fragment length polymorphism (RFLP) and variable number of tandem repeats (VNTR). Genetic polymorphism acts directly or by linked groups of SNPs or non-linked groups of genes in different chromosomes. ${ }^{[2]}$

\section{Gene polymorphism related to ARDS}

Researchers have screened the polymorphism of many genes related to ARDS and studied the effects of some genes. This paper reviews the research results.

\section{Angiotensin-converting enzyme (ACE)}

Activation of the renin-angiotensin system (RAS) can affect the participation of fibroblasts, alveolar epithelial cells and vascular endothelial cells in the pathological process of ARDS by changing pulmonary vascular permeability and angiostasis. ACE is a key enzyme in RAS. Animal studies have proven that ACE gene knockout mice could protect themselves from acute lung injury (ALI) induced by acid inhalation and sepsis and that pretreatment with Enalapril might alleviate pulmonary inflammation caused by endotoxin. ${ }^{[3,4]}$ Human ACE gene, located at chromosome 17q23, has RFLP, consisting of a 287-bp insertion/deletion of an Alu repeat in the 16 th intron of the ACE gene. ${ }^{[5]}$ 
Marshall et al..$^{[6]}$ have compared ACE genotypes of ARDS patients, patients with respiratory failure but without ARDS, patients who undertook coronary artery bypass grafting and healthy people, and found that the frequency of DD genotype in ARDS patients was significantly higher than that in the other three groups and that the fatality rate of ARDS patients with the DD genotype was much higher. Jerng et al. ${ }^{[7]}$ compared ACE genotypes of ARDS patients, patients with respiratory failure and high risk for ARDS but without ARDS and healthy people in the Chinese population and showed that the survival rate of patients with II genotype was higher than those with DD genotype, but found no association between the frequency of D allele and susceptibility to ARDS. Similarly, Lu et al. ${ }^{[8]}$ have not found any association between I/D polymorphism of ACE gene and susceptibility to ALI in the Chinese Han population, but reported that the fatality rate of ALI patients with the DD genotype was higher. Matsuda et al. ${ }^{[9]}$ have done a meta-analysis of seven studies on the association between I/D polymorphism of ACE gene and susceptibility to and fatality rate of ARDS (532 ARDS patients, 1432 non-ARDS patients and 3032 healthy controls in total) and found no association between I/D polymorphism of ACE gene and susceptibility to ARDSI and the possible association between I/D polymorphism and the fatality rate of ALI and/or ARDS in the Asian population.

\section{Extracellular superoxide dismutase 3 (SOD3)}

SOD3, a member of the human superoxide dismutase family, is an important extracellular antioxidant enzyme. Animal studies have indicated that SOD3 gene knockout mice had higher susceptibility to ALI induced by lipopolysaccharides (LPS) and stronger response to pulmonary inflammation; on the contrary, the overexpressed SOD3 genes alleviated inflammatory response induced by LPS. The results suggest that SOD3 genes might resist ALI. ${ }^{[10]}$ Arcaroli et al..$^{[1]}$ have genotyped the SOD3 genes of two groups of patients with ALI relevant to infection and found that patients with GCCT haploid needed mechanical ventilation and had lower risk of death.

\section{Interleukin-10 (IL-10)}

IL-10 can inhibit the expression of pro-inflammatory cytokines. The 5' flanking region of IL-10 gene has several gene polymorphisms, which act through haploids formed by linkage. It has been known that GCC, ACC and ATA haploids (located at the $-1082,-819$ and -592 loci of IL-10 gene) are closely related to the expression level of IL-10; individuals with the GCC/GCC genotype have shown the highest level of IL-10 expression. ${ }^{[12]}$ Gong et al. ${ }^{[13]}$ made a nested case-control study of patients with risk factors for ARDS and found that the severity, incidence of organ function failure and fatality rate of ARDS patients with the -1082G/G genotype (high IL-10 expression) were lower than those of patients with other genotypes.

\section{Myosin light chain kinase (MLCK)}

Endothelial barrier damage is one of the pathogeneses of ARDS. MLCK plays an important role in cytoskeletal rearrangement by phosphorylation of the myosin light chain and influence of the interaction between actin and myosin; therefore, it is crucial to the integrity of the endothelial barrier. MLCK gene knockout mice can protect from ALI caused by LPS. ${ }^{[14]}$ Eutamene et al. ${ }^{[15]}$ pretreated mice with MLCK inhibitor and induced lung injury by administration of LPS into airways via a tracheal catheter and found that the airway inflammation and epithelial permeability of the mice pretreated with inhibitor were lower. Gao et al. ${ }^{[16]}$ detected MLCK genes of ALI patients with sepsis, sepsis patients and healthy controls and found 51 SNPs in MLCK genes, of which a few polymorphisms were related to the risk of ALI and sepsis. Christie et al. ${ }^{[17]}$ have also found the association between the polymorphism of MLCK gene and ALI in injured patients.

\section{Nuclear factor erythroid 2-related factor 2 (NRF2)}

NRF2 is a critical transcription factor when the cells regulate anti-oxidative stress. Physiologically, it binds with Keapl, a cytoplasmic molecular chaperone and is relatively inhibited. In anti-oxidative stress, NRF2 uncouples with Keapl, moves into the nucleus, binds with anti-oxidative response element (ARE), activates the gene expression of Phase II detoxification and antioxidant enzymes regulated by ARE and aids cells in anti-oxidative stress. Marzec et al. ${ }^{[18]}$ have sequenced human NRF2 genes and detected three SNPs in promoters: $-617 \mathrm{C} / \mathrm{A},-651 \mathrm{G} / \mathrm{A}$ and $-653 \mathrm{~A} / \mathrm{G}$. SNP of the -617 locus might cause the loss of NRF2 function. In a further study, it was found that patients with the-617A SNP were more susceptible to ALI than patients with wild genotypes (OR 6.44, 95\% CI 1.34-30.8, $P=0.021$ ).

\section{Pre-B cell colony-enhancing factor (PBEF)}

$\mathrm{PBEF}$ is a cytokine whose expression is induced by mechanical stretch, tension and other inflammatory factors. In recent years, studies have indicated that PBEF participated in the pathological process of ARDS by inflammation, immunity, oxidative stress and apoptosis. Ye et al. ${ }^{[19]}$ have compared PBEF genotypes of ALI patients with sepsis, severe sepsis patients without ALI and healthy controls in the Caucasian population and found that the PBEF gene had two gene polymorphisms $(-1001 \mathrm{~T} / \mathrm{G}$ and $-1543 \mathrm{C} / \mathrm{T})$. ALI risk of individuals with GC haploid increased significantly (7.7 times), while that of those with TT haploid was quite low. Bajwa et al. ${ }^{[20]}$ have compared PBEF gene polymorphism among 
more than two types of ARDS patients and non-ARDS patients exposed to ARDS risks, and found that ARDS risk (OR 1.35) and Intensive Care Unit fatality rate of patients with -1001G SNP increased, while ARDS risk (OR 0.66), the fatality rate at $28 \mathrm{~d}$ and $60 \mathrm{~d}$ and the duration (days) of mechanical ventilation of patients with -1543T SNP decreased.

\section{Surfactant protein B (SP-B)}

SPs, expressed in alveolar epithelial cells type II, reduce alveolar surface tension, preventing alveoli from collapse. In the development of ALI, injuries to alveolar epithelial cells cause the decrease of SPs in bronchoalveolar lavage and the increase of SPs in plasma. It has been reported that the increase of SPs in plasma was closely associated with adverse clinical outcome. ${ }^{[21]}$ Floros et al. ${ }^{[22]}$ have reported that-I/D polymorphism in the 4 th intron of the SP-B gene was related to neonate respiratory distress syndrome. However, the differences of the gene polymorphism have not been detected between adult ARDS patients and healthy controls. After further comparison of the data stratified by gender and cause, it was found that the female patients with the gene polymorphism and exposed to direct lung injuries such as pneumonia and accidental inhalation were more prone to ARDS. ${ }^{[23]}$ Currier et al. ${ }^{[24]}$ have detected that-VNTR in the 4th intron of the SP-B gene was associated with the fatality rate at $60 \mathrm{~d}$. Quasney et al. ${ }^{[25]}$ have found-C/T SNP at the +1580 locus in the $4^{\text {th }}$ exon of SP-B gene; in patients exposed to lung injuries directly, the risk of ARDS of those with $+1580 \mathrm{C}$ was higher than those with +1580T.

\section{Tumor necrosis factor (TNF)}

TNF, a proinflamatory factor, is involved in the pathological process of ALI by the release of other cell factors and the increase of endothelial cell permeability. Some studies have shown that the increase of TNF in plasma was positively related to the severity and fatality rate of ARDS. Gong et al. ${ }^{[26]}$ have detected -G/A SNP at the -308 locus of TNF gene and found that the risk and fatality rate of ARDS in patients with such SNPs were both lower.

\section{Vascular endothelial growth factor (VEGF)}

VEGF can influence angiogenesis, proliferation and transition of vascular endothelial cells and endothelial barrier permeability in the development of ALI pulmonary edema. In a mouse model, high levels of VEGF protected the experimental animals from ALI induced by high concentrations of oxygen. ${ }^{[27]}$ Medford et al. ${ }^{[28]}$ have genotyped and compared the VEGF genes of ARDS patients and non-ARDS patients exposed to ARDS risk and found that C/T SNP at the +936 locus of the VEGF gene was associated with high ARDS susceptibility and
APACHE III scoring and not related to the fatality rate. Yet, Zhai et al..$^{[2]}$ have found that the +936TT, +936CT, and +TT genotypes and TCT haploids of VEGF gene were related to a high fatality rate of ARDS and VEGF in the plasma of patients with the three genotypes were low, indicating that high VEGF might resist ARDS.

\section{Problems and prospects}

Research on the gene polymorphism of ARDS is currently in the preclinical stage and the results are not consistent. The following aspects should be considered when analyzing the relationship between ARDS and the gene polymorphism.

Because of the lack of specific diagnostic criteria for ARDS, non-ARDS patients might be mistaken as subjects, resulting in wrong association between genes and diseases. ARDS is a clinical syndrome; therefore, the diagnostic criteria cannot be absolutely objective, specific and repeatable. In addition, the clinical manifestations of ARDS show obvious heterogeneity influenced by age, general health and pathogenic factors. Thus, when conducting or analyzing such researches, we should specify and optimize diagnostic criteria to ensure the true association between ARDS and the gene polymorphism, but not that between the gene polymorphism and mixed factors.

The distribution of allelic frequency in different populations is not consistent. The interaction between genes and environment may also affect the development of diseases. For instance, the frequency of allele D in ACE gene in the Western population is obviously higher than that in the Chinese population (51-56\% and $30-45 \%$, respectively); the association between the gene polymorphism and ARDS in the Western population is not consistent with that in the Chinese population. ${ }^{[8]}$ Therefore, the race, ethnic group and living environment of the subjects should be specified when studying and reporting the association between gene polymorphism and disease.

The study design and interventions should be rigorous, which involve choosing proper controls, obeying the law of genetic equilibrium, avoiding genotyping mistakes and using right statistical analyses. In exploring the relationship between the gene polymorphism and ARDS, some researches choose a healthy population or hospitalized nonARDS patients as controls. Actually, the optimal controls in such researches should be non-ARDS patients exposed to the same risk factors as ARDS patients. With the proper controls, the true association between gene polymorphism and ARDS could be revealed.

Most of the published studies use small samples in a single population, and their results are not consistent. The 
results need to be verified by large samples in different populations. ${ }^{[2,30-32]}$

With the development of genetics, especially gene medicine, ARDS can be studied and known at the genetic level. In the future, ARDS-related gene polymorphism may play an important role in identifying susceptibility risk, assessing prognosis revealing new etiology and pathophysiological mechanisms, and optimizing diagnosis and treatment. The existing research results have presented a promising future. With further study, more exciting results could be obtained gradually.

\section{REFERENCES}

1. Ware LB, Matthay MA. The acute respiratory distress syndrome. N Engl J Med 2000;342:1334-49.

2. Cardinal-Fernandez P, Nin N, Lorente JA. Acute lung injury and acute respiratorydistress syndrome: A genomic perspective. Med Intensiva 2011;35:361-72.

3. Imai Y, Kuba K, Rao S, Huan Y, Guo F, Guan B, et al. Angiotensinconverting enzyme 2 protects from severe acute lung failure. Nature 2005;436:112-6.

4. Arndt PG, Young SK, Poch KR, Nick JA, Falk S, Schrier RW, et al. Systemic inhibition of the angiotensin-converting enzyme limits lipopolysaccharide-induced lungneutrophils recruitment through both bradykinin and angiotensin II-regulated pathways. J Immunol 2006;177:7233-41.

5. Adamzik M, Frey U, Sixt S, Knemeyer L, Beiderlinden M, Peters J, et al. ACE I /D but not AGT (-6) A/G polymorphism is a risk factor for mortality in ARDS. Eur Respir J 2007;29:482-8.

6. Marshall RP, Webb S, Bellingan GJ, Montgomery HE, Chaudhari B, McAnulty RJ, et al. Angiotensin converting enzyme insertion/deletion polymorphism is associated with susceptibility and outcome in acute respiratory distress syndrome. Am J Respir Crit Care Med 2002;166:646-50.

7. Jerng JS, Yu CJ, Wang HC, Chen KY, Cheng SL, Yang PC. Polymorphism of the angiotensin converting enzyme gene affects the outcome of acute respiratory distress syndrome. Crit Care Med 2006;34:1001-6.

8. Lu XM, Chen GJ, Yang Y, Qui HB. Angiotensin-converting enzyme polymorphism affects outcome of local Chinese with acute lung injury. Respir Med 2011;105:1485-90.

9. Matsuda A, Kishi T, Jacob A, Aziz M, Wang P. Association between insertion/deletion polymorphism in Angiotensin-converting enzyme gene and acute lung injury /acute respiratory distress syndrome: A meta-analysis. BMC Med Genet 2012;13:76.

10. Bowler RP, Nicks M, Tran K, Tanner G, Chang LY, Young SK, et al. Extracellular superoxide dismutase attenuates lipopolysaccharide induced neutrophilic inflammation. Am J Respir Cell Mol Biol 2004;31:432-9.

11. Arcaroli JJ, Hokanson JE, Abraham E, Geraci M, Murphy JR, Bowler RP, et al. Extracellular superoxide dismutase haplotypes are associated with acute lung injury and mortality. Am J Respir Crit Care Med 2009;179:105-12.

12. Crawley E, Kay R, Sillibourne J, Patel P, Hutchinson I, Woo P. Polymorphic haplotypes of the interleukin-10 5'flanking region determine variable interleukin-10 transcription and are associated with particular phenotypes of juvenile arthritis. Arthritis Rheum 1999;42:1101-8.

13. Gong MN, Thompson BT, Williams PL, Zhou W, Wang MZ, Pothier $\mathrm{L}$, et al. Interleukin-10 polymorphism in position - 1082 and acute respiratory distress syndrome. Eur Respir J 2006;27:674-81.
14. Wainwright MS, Rossi J, Schavocky J, Crawford S, Steinhorn D, Velentza AV, et al. Protein kinase involved in lung injury susceptibility: Evidence from enzyme isoform genetic knockout and in vivo inhibitor treatment. Proc Natl Acad Sci USA 2003;100:6233-8.

15. Eutamene H, Theodorou V, Schmidlin F, Tondereau V, Garcia-Villar $\mathrm{R}$, Salvador-Cartier C, et al. LPS-induced lung inflammation is linked to increased epithelial permeability: Role of MLCK. Eur Resp J 2005;25:789-96.

16. Gao L, Grant A, Halder I, Brower R, Sevransky J, Maloney JP, et al. Novel polymorphisms in the myosin light chain kinase gene confer risk for acute lung injury. Am J Respir Cell Mol Biol 2006;34:487-95.

17. Christie JD, Ma SF, Aplenc R, Li M, Lanken PN, Shah CV, et al. Variation in the myosin light chain kinase gene is associated with development of acute lung injury after major trauma. Crit Care Med 2008;36:2794-800.

18. Marzec JM, Christie JD, Reddy SP, Jedlicka AE, Vuong H, Lanken PN, et al. Functional polymorphisms in the transcription factor NRF2 in humans increase the risk of acute lung injury. FASEB J 2007;21:2237-46.

19. Ye SQ, Simon BA, Maloney JP, Zambelli-Weiner A, Gao L, Grant A, et al. Pre-B-cell colony-enhancing factor as a potential novel biomarker in acute lung injury. Am J Respir Crit Care Med 2005;171:361-70.

20. Bajwa EK, Yu CL, Gong MN, Thompson BT, Christiani DC. Pre-Bcell colony-enhancing factor gene polymorphisms and risk of acute respiratory distress syndrome. Crit Care Med 2007;35:1290-95.

21. Eisner MD, Parsons PE, Matthay MA, Ware L, Greene K; Acute Respiratory Distress Syndrome Network. Plasma surfactant protein levels and clinical outcomes in patients with acute lung injury. Thorax 2003;58:983-8.

22. Floros J, Veletza SV, Kotikalapudi P, Krizkova L, Karinch AM, Friedman C, et al. Dinucleotide repeats in the human surfactant protein-B gene and respiratory distress syndrome. Biochem J 1995;305:583-90.

23. Gong MN, Wei Z, Xu LL, Miller DP, Thompson BT, Christiani DC. Polymorphism in the surfactant protein-B gene, gender, and the risk of direct pulmonary injury and ARDS. Chest 2004;125:203-11.

24. Currier PF, Gong MN, Zhai R, Pothier LJ, Boyce PD, Xu L, et al. Surfactant protein-B polymorphisms and mortality in the acute respiratory distress syndrome. Crit Care Med 2008;36:2511-6.

25. Quasney MW, Waterer GW, Dahmer MK, Kron GK, Zhang Q, Kessler LA, et al. Association between surfactant protein-B + 1580 polymorphism and the risk of respiratory failure in adults with community-acquired pneumonia. Crit Care Med 2004;32:1115-9.

26. Gong MN, Zhou W, Williams PL, Thompson BT, Pothier L, Boyce P, et al. 308GA and TNFB polymorphisms in acute respiratory distress syndrome. Eur Respir J 2005;26:382-9.

27. Corne J, Chupp G, Lee CG, Homer RJ, Zhu Z, Chen Q, et al. IL-13 stimulates vascular endothelial growth factor and protects against hyperoxic lung injury. J Clin Invest 2000;106:783-91.

28. Medford AR, Keen LJ, Bidwell JL, Millar AB. Vascular endothelial growth factor gene polymorphism and acute respiratory distress syndrome. Thorax 2005;60:244-8.

29. Zhai R, Gong MN, Zhou W, Thompson TB, Kraft P, Su L, et al. Genotypes and haplotypes of the VEGF gene are associated with higher mortality and lower VEGF plasma levels in patients with ARDS. Thorax 2007;62:718-22.

30. Gong MN. Genetic epidemiology of acute respiratory distress syndrome: Implication for future prevention and treatment. Clin Chest Med 2006;27:705-24.

31. Dong HJ, Luo YC, Gao FH. Clinical study on the strategy of fluid management for ARDS patients. Acta Acad Med CPAPF 2011;20:535-7.

32. Wang CM, Zhang PR, Zhang Y. Research on correlation between complicated acute lung injury/acute respiratory distress syndrome and plasminogen activator inhibitor- 1 in patients with acute cerebral infarction. J Clin Med Prac 2012;16:23-5.

How to cite this article: Liu C, Li J. Role of genetic factors in the development of acute respiratory distress syndrome. J TransI Intern Med 2014;2:107-10.

Source of Support: Nil, Conflict of Interest: None declared 